\title{
Missing Scholars: \\ Social Exclusion at the Indian Institutes of Management
}

\author{
Siddharth Joshi and Deepak Malghan§
}

(Data Update, January 2018)

The Indian Institutes of Management (IIMs) constitute a tiny sliver of India's higher educational institutions. Despite their negligible size (enrolling under ten thousand students across twenty independent institutions), they exert a disproportionate normative influence on debates surrounding higher education in general and management education in particular. As standard-bearers, the normative choices that these institutions make helps shape the landscape in which other institutions operate. Even when all that is commendable and worth emulating at IIMs does not diffuse broadly, the fault lines at IIMs reverberate far beyond the boundaries of these exalted enclaves. With the Indian Institutes of Management Act being notified in the official gazette (IIM Act), the IIMs now have an even greater ability to shape the contours of moral imagination for millions of young Indians.

IIMs suffer from an acute social diversity deficit in their faculty composition. New data that we have obtained since we first published faculty diversity data at IIM, adds even more ballast to the arguments made at the time. Out of 642 faculty members covered by this data, only two are from the Scheduled Castes (SC) group, and none form the Scheduled Tribes (ST) group (and only thirteen belong to the Other Backward Classes, or OBC group). As a public institution, this bleak picture severely undermines the legitimacy of IIMs. In this sequel, we chronicle over four decades of omissions and commissions including willful (and often skillful) skirting of constitutional and statutory provisions that have contributed to what we term as the "missing scholars" phenomenon.

$\S$ Malghan is on the faculty at the Centre for Public Policy (CPP), Indian Institute of Management Bangalore (IIMB). Joshi is an independent scholar and a Fellow of IIMB (2017). The views expressed here are wholly personal and do not reflect the institutional position(s) of CPP, or IIMB. Email: mailsiddj@gmail.com (Joshi); dmalghan@iimb.ernet.in (Malghan). 
First, we provide the latest data available on faculty social diversity at IIMs as well as discuss data limitations. We then argue that the doctoral programmes at IIMs must take a large part of the blame for this extant social diversity deficit. For over four decades, the doctoral programmes at IIMs that also account for about a third of all current faculty members at these institutions have brazenly flouted affirmative action provisions for public institutions. Finally, we make a normative case for symbolic, if not actual reparations, and identify measures to ameliorate the social diversity deficit.

\section{Social Diversity Deficit at IIMs}

Table-1 records census-category social group data for faculty at IIMs where we were able to obtain such data. This table contains data for over five-hundred faculty members in ten out of the thirteen IIMs that have a permanent faculty body, and is updated from a much smaller dataset published previously. Out of the 642 faculty members across these ten IIMs, only four are from the Scheduled Castes (SC) group and a solitary faculty member is from the Scheduled Tribes (ST) group. Table-1 potentially overstates the diversity deficit among faculty at IIMs for two reasons. First, IIMAhmedabad (IIMA) administratively classifies all its faculty members as belonging to the “others" category. ${ }^{1}$ Thus, any IIMA faculty member belonging to SC or ST communities are also counted in the "others" category. ${ }^{2}$ Second, the source data at all IIMs is selfreported, and faculty members belonging to SC or ST groups might have chosen to mask their social group identity. At an immediate empirical level, anecdotal evidence suggests that overcoming either of these two limitations in data will not result in any significant revision of the numbers presented in Table-1. It is very unlikely that the social group composition at IIMA is drastically different from those at other IIMs; or that there is massive underreporting of faculty belonging to SC and ST groups at IIMs other than IIMA. At a more normative level, both these sources of data limitation point to the pernicious consequences of socially monochromatic faculty bodies. 


\begin{tabular}{|c|c|c|c|c|}
\hline $\begin{array}{l}\text { Institution (year of } \\
\text { establishment) }\end{array}$ & SC & ST & OTH & TOTAL \\
\hline IIM, Calcutta (1961) & 0 & 0 & 83 & 83 \\
\hline IIM, Ahmedabad (1961) & 0 & 0 & 96 & 96 \\
\hline IIM, Bangalore (1973) & 0 & 0 & 86 & 86 \\
\hline IIM, Lucknow (1984) & 1 & 0 & 73 & 74 \\
\hline IIM, Indore (1996) & 0 & 0 & 88 & 88 \\
\hline IIM, Kozhikode (1996) & 1 & 0 & 65 & 66 \\
\hline IIM, Shillong (2007) & 1 & 1 & 20 & 22 \\
\hline IIM, Rohtak (2009) & 1 & 0 & 13 & 14 \\
\hline IIM, Raipur (2010) & 0 & 0 & 14 & 14 \\
\hline IIM, Ranchi (2010) & 0 & 0 & 15 & 15 \\
\hline IIM, Kashipur (2011) & 0 & 0 & 33 & 33 \\
\hline $\begin{array}{l}\text { IIM, Tiruchirapalli } \\
(2011)\end{array}$ & 0 & 0 & 19 & 19 \\
\hline IIM, Udaipur (2011) & 0 & 0 & 32 & 32 \\
\hline Totals & 4 & 1 & 637 & 642 \\
\hline
\end{tabular}

Table-1 Distribution of faculty by census categories. Data was obtained through multiple Right to Information (RTI) applications filed at individual IIMs as well as with the Ministry of Human Resource Development (MHRD), Government of India Of the 637 faculty members belonging to the "others" group, 17 belong to the OBC category. Thus, even with a four-fold division, $96.6 \%$ of IIM faculty members are drawn from the dominant social groups. The data for IIM-Ahmedabad (IIMA) potentially understates faculty members belonging to SC or ST groups. As a matter of policy, IIMA administratively classifies all faculty members as belonging to the "Others" group. Also see main text for other data limitations. 
These data limitations only strengthen the case for urgent ameliorative steps to improve social diversity at IIMs. If there is some negligible under reporting of faculty belonging to SC or ST groups, it is because of the stigma of belonging to socially marginalized groups at elite institutions like IIMs. The IIMs like all other public institutions in India follow statutorily mandated affirmative action in the form of reserved seats for applicants from historically marginalized social groups in their flagship MBA programme. At elite public institutions in India, the students from the so-called "reserved categories" are widely seen as trespassers if not usurpers. In such a climate, handful of faculty members from historically marginalized sections of the society might choose to keep their social group identity under wraps.

To be sure, the limitations in data reported above is also related to IIMs believing that collecting any social group data is akin to further deepening social fault lines. The IIMs have marshaled the social construction argument into an effective arsenal to defend against pressures for social inclusion and diversity. The duplicity inherent in their ambivalent commitment to the social construction argument is best seen in the contradictory responses to our Right to Information (RTI) requests. Thus, several institutes have a "policy" to preferentially recruit faculty from historically under-represented social groups but these very same institutes also have a "policy" to not ask for social group data, even on a voluntary basis. ${ }^{3}$ 


\begin{tabular}{|c|c|c|c|}
\hline \multirow{2}{*}{$\begin{array}{l}\text { Institution (Year of } \\
\text { establishment of the } \\
\text { FPM Programme) }\end{array}$} & \multicolumn{3}{|c|}{ Doctoral (FPM) Students at IIMs } \\
\hline & $\begin{array}{c}\text { Graduated } \\
\text { (as of April } 5^{\text {th }} 2017 \text { ) }\end{array}$ & $\begin{array}{l}\text { Currently Enrolled } \\
\text { (as of April } 5^{\text {th }} 2017 \text { ) }\end{array}$ & Total \\
\hline $\begin{array}{l}\text { IIM Ahmedabad } \\
(1971)\end{array}$ & 331 & 103 & 434 \\
\hline IIM Calcutta (1971) & 193 & 98 & 291 \\
\hline IIM Bangalore (1976) & 255 & 85 & 340 \\
\hline IIM Lucknow (2000) & 41 & 64 & 105 \\
\hline IIM Indore (2006) & 57 & 51 & 108 \\
\hline IIM Kozhikode (2007) & 18 & 51 & 69 \\
\hline Total & 895 & 452 & 1347 \\
\hline Missing Scholars & & $\sim 270$ & \\
\hline
\end{tabular}

Table-2 Conservative estimate of "Missing Scholars" across the six largest doctoral programmes in the IIM system. See main text for details.

\section{Trapped in a Matrix}

The IIMs have often made the case that the biggest driver of the diversity deficit reported in Table-1 is the lack of a sufficiently qualified faculty applicant pool from historically underrepresented sections of the society. 4 This betrays the fact that like all major research universities, IIMs are both "producers" and "consumers" of faculty talent. Data on educational background of current faculty shows that nearly a third of all faculty at institutions in Table- 1 received their doctoral training at these very institutes. The first doctoral programmes (called the FPM, or the Fellow Programme in Management) at IIMs were inaugurated in 1971 and in the more than four decades since, the six largest 
programmes at IIMs established in the twentieth century have enrolled more than thirteen hundred doctoral scholars (Table -2). As public institutions, IIMs are statutorily mandated to use reservations as an affirmative action tool in admissions to their doctoral programmes. ${ }^{5}$ What then explains IIMs' inability to generate a large enough faculty applicant pool that is socially diverse?

Over a four decade period, IIMs have paid scant attention to diversity or inclusion in their doctoral programmes that are the nurseries for future IIM faculty. Administrative data gathered from various IIMs through multiple RTI requests suggests that this neglect has been callous at best, and more often willful and deliberate. IIMs have betrayed their social contract (as a public institution) by using duplicitous arguments that have served as no more than a fig leaf. Responses to our RTI requests indicate that one of the most common methods adopted by IIMs to circumvent affirmative action provisions has been to invoke what we term the "null matrix argument". If there is no positive lower-bound, or an upper-bound on the number of students that are admitted into the doctoral program each year, a social group quota-based affirmative action cannot be made operational. 6 This is at best an ingenious argument to maintain structures of social exclusion.

It is nobody's case that specialized doctoral programs can, or should have a "fixed" number of positions available in any given year. Doctoral admissions ought not to be caught up in a seat-matrix quagmire that afflicts undergraduate and post-graduate admissions in India. However even a half-hearted recognition of social diversity and social inclusion as worthy goals would have inspired creative thinking from institutions that take great pride in referring to themselves by that public relations misnomer - "thought leaders". Unfortunately, the thought leaders at IIMs have thus far, willfully or otherwise, failed to apply their minds to questions of diversity or inclusion. While a doctoral programme might not have the number of positions available each year set in stone, every doctoral program has limited flexibility in terms of how many students they can have in residence at any given time (given faculty numbers, faculty research interests, and resource constraints). 
The duplicity and insincerity underlying the null matrix argument is exposed by the willful and skillful deceit used by IIMs in filling up vacant positions for their doctoral programmes through a covert waiting list process. None of the IIMs in their doctoral programme admissions advertisement discuss a waiting list process. An admissions waiting list is after all logically inconsistent with the null matrix argument. Anecdotal evidence from several IIMs suggests that IIMs do not operate an overt waiting list in order to cover up for the charade that is the null matrix argument. A recent response to an RTI application at IIM-Ahmedabad indicates that IIMs, now emboldened by the unprecedented autonomy on the anvil have started using an open waiting list - one that is apparently compatible with the null matrix argument. ${ }^{7}$

The skullduggery around affirmative action in the doctoral programs at IIMs has often been justified on the grounds that some of the older institutions no longer receive any direct funding from the government. At an empirical level, this is a factually incorrect characterization of the doctoral programs at IIMs. Institutes at Ahmedabad, Kolkata, and Bengaluru (the three oldest IIMs with the largest doctoral programs) have all received

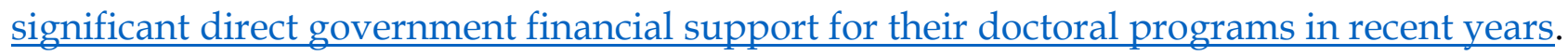
More broadly, this is a specious argument for institutions that have been built with massive public support. Like much of the rest of the world, public institutions in India have been under relentless attack in the last two decades. The funding argument that IIMs invoke is somewhat of a self-fulfilling prophecy that sits well with institutions that have for a long time pioneered a wholly misconstrued notion of institutional autonomy. Autonomy for IIMs has largely meant a receding, if not complete secession from a compact that underlies a public institution.

Given the nature of doctoral programmes at research institutions, it is indeed not possible, or even desirable to use the formulaic quota based reservation policy. Indeed, there is not a single world class academic institution that uses numerical quota in recruiting doctoral students. However, in the last three decades or so, the best doctoral programs around the world across academic disciplines including management have redoubled their commitment to social inclusion, and efforts to recruit a diverse doctoral student body. These efforts have pioneered a host of alternatives to numerical quota. The IIMs, however have 
done precious little beyond offering well-rehearsed platitudes about their commitment to diversity; and even this "cheap talk", devoid of any real commitment to diversity or inclusion has often been a response to societal and state pressure.

\section{The Missing Scholars, and the Case for Moral Reparations}

Writing in the early 1990s, the Nobel Laureate economist, Amartya Sen coined the influential term "missing women" to describe lower than biologically expected sex ratios as a result of son preference leading to sex-selective abortions, or female infanticide. The four decade record of omissions and commissions at IIMs' doctoral programmes is akin to cultural prejudices that leads to "missing women". The deliberate circumvention of constitutional and statutory provisions by IIMs has led to what we term "missing scholars."

As reported in Table-2, IIMs that have graduated significant number of doctoral cohorts have cumulatively admitted over thirteen hundred doctoral scholars (as of the end of academic year 2016-17). A conservative lower bound on the number of missing scholars is at least 270. We arrived at this estimate for missing scholars that the IIMs have failed to produce by using a diversity deficit proportion of 20\% (IIMs are obligated to meet the statutorily mandated $49.5 \%$ target). While IIMs do not collect social group data on doctoral programme applicants, anecdotal evidence suggests a diversity deficit among doctoral scholars at IIMs that is just as acute as the one we have reported for faculty in Table- 1 . Our missing scholar computation generously provides for nearly $30 \%$ of the doctoral scholars at IIMs as belonging to historically under-represented social groups (SC, ST, or OBC). ${ }^{8}$ There are currently 208 faculty members across IIMs who received their doctoral training at one of the IIMs. This suggests that the quantum of missing scholars represents at least $130 \%$ of total IIM-trained faculty members.

As we have shown, the missing scholars are a direct consequence of over four decades of apathy, duplicity, and at times even skillful deceit. An empathetic and honest self-appraisal, as well as an acknowledgement of IIMs' indefensible history of missing scholars is a necessary preliminary to any corrective, or even ameliorative steps. Any 
honest assessment of the history of doctoral programmes at IIMs can only conclude that these institutions owe an extraordinarily large moral debt to society at large and the historically marginalized in particular. The history of missing scholars is however not only about the quantum of debts that have been incurred by IIMs, but about how these institutions have accumulated their debts by consistent violation of their social contract, abdication of their constitutional obligations, and willful violation of statuary provisions. Reconciling with this -- albeit shameful -- history of missing scholars will pave the way for a creative response that is restorative rather than retributive.

Given the enormous normative influence of IIMs, consequences of missing scholars reverberate beyond the hallowed portals of these institutions or even the broader academy. The normative structures of exclusion at IIMs that produce missing scholars are also the ones that directly engender documented social exclusion in higher echelons of Indian management praxis. While the enormity of missing scholars probably justifies a case for retributive reparations, we call instead for a more constructive restorative reparations - and moral reparations instead of material reparations. Moral reparation will mean acknowledgement of not only the instrumental consequences of missing scholars but the complicity and failure of moral imagination across four decades and several generations of faculty and administrators at IIMs.

Restorative reparation, rather than a retributive reparation also recognizes the fact that beyond access, inclusion, or diversity, the most significant and long-lasting damage from IIM's violation of constitutional obligations is the impoverishment of our collective understanding of management, business, government, and society. A socially diverse student body (especially doctoral research scholars) not only reflects institutional commitment to inclusion but directly impacts both the form and quality of knowledge that is generated by an academic institution - one of the primary missions of institutions such as IIMs. Several notable individual faculty exceptions notwithstanding, IIMs have largely abdicated their mission as public institutes of management and reduced themselves to narrow business schools. Social diversity not only contributes to intellectual diversity but aids the pursuit of academic excellence - what is, or at any rate what ought to be the central pursuit at IIMs. 
A practical programme of reparation must of course grapple with the contentious questions beyond apathy and indifference that produced missing scholars in the first place. The most contentious of these questions relates to central goals of affirmative action. Affirmative action programmes at Indian institutions are often wrongly characterized as a redistribution policy. Affirmative action programmes are also not meant to tweak the social composition of elite institutions to exactly mirror the demography of society at large. Affirmative action at elite institutions recognizes that such institutions are normmakers and social diversity only adds to social legitimacy of institutions - especially at public institutions such as IIMs.

The relentless erosion of the social contract between a public institution and the society at large is in the ultimate analysis, the principal driver of the missing scholars conundrum that we have detailed here. Any attempt to redress the problem must begin by renewing and perhaps even reinventing a social contract that puts diversity, and social inclusion at its core. IIMs have been the "thought leaders," or more accurately cheer leaders of attacks on the idea of a public university in India. IIMs' receding from the public sphere has been normalized by (largely specious) institutional autonomy arguments. Surely, institutional autonomy is central to academic excellence. Islands of excellence within the IIM system have indeed been fueled by great flexibility and autonomy that is conspicuously absent at the vast majority of Indian institutions. However, alongside this modest academic excellence, IIMs have also clamored for an autonomy that is not subject to searching social scrutiny beyond statutorily mandated fiscal audits. Such claims have hinged on financial independence that is in turn predicated on turning students at a public institution into customers paying for private services. For example, a classroom with diverse student perspectives can critically engage with the political economy of large-scale physical infrastructure (a topic currently in vogue at IIMs) in ways that is not possible when the lecture halls are filled with paying customers. At IIMs, the misguided elevation of financial autonomy as the fountainhead of all academic autonomy has had the effect of reducing, not increasing that most central autonomy for a university - intellectual autonomy. A disproportionate focus on revenue or profit maximization can never foster 
an environment of critical enquiry. The diversity deficit that we have chronicled here is of much limited consequence for a customer service organization unlike for a professoriate.

The IIMs (and especially the older and larger IIMs) have also used their financial muscle in largely self-serving ways that further alienates them from their public mission. The debt that IIMs owe cannot be reconciled without first recovering IIMs as public institutions. A public institution cannot be an enclave - social, or intellectual. The idea of a symbolic moral reparation that we have advanced here is only tenable in the context of a public institution. Reimagining IIMs as public institutions is the only morally enabling framework in which decades of neglect of inclusion and diversity imperatives can be addressed.

Notwithstanding the periodic and largely symbolic chastisement of IIMs for their neglect of diversity and inclusion goals, the state has been every bit as complicit as the institutions themselves in precipitating the missing scholars phenomenon that we have described. Egged on by the aspirations and preferences of the cheering urban upwardly mobile class, the state has utterly failed in its fiduciary duty to ensure that IIMs craft an inclusion and diversity programme that is consistent with their constitutional obligations. The new IIM Act offers the state as well as the individual IIMs an opportunity to redefine their respective roles in the governance of a public university (IIMs are slated to become full-fledged degree granting universities when the Act is implemented). The IIM Act offers the flexibility for each of the IIMs to design their own diversity and inclusion programmes. IIMs are not one monolithic institution, but twenty different institutions with vastly different historical legacies. Each individual IIM must be accorded the flexibility to address the missing scholars problem independently. However, the state must ensure that IIMs make continuous and actual demonstrable progress. The current rhetoric at IIMs on inclusion and diversity characterized by a deliberately cultivated vacuity. The IIM Act offers a framework for the state and the IIMs to deliberatively set the broad normative contours of diversity and inclusion without direct state interference. Such a deliberative approach also eliminates the need for a top-down and formulaic approach that is easy to comply with in letter but not always in spirit. However, no institutional autonomy 
argument can serve as a plausible normative defense of missing scholars that we have reported here.

The IIM Act offers a window of opportunity to reverse decades of shameful neglect. Will the IIMs rise up to the occasion? The answer to this question will have far reaching consequences beyond the tiny corner of higher education that these institutes occupy. Indeed, how (if) IIMs address the missing scholars problem will serve as a guide to the future of the public university in India.

\section{Notes}

1 IIMA response to Ministry of Human Resource Development, Government of India letter dated, 16/12/2015 (letter obtained under RTI Act from IIMA).

2 IIM Ahmedabad, like all other IIMs, used the term "General" to refer to the "Others" census group.

3 For example, in response to a RTI application concerning faculty social diversity, IIM Bangalore responded that "[i]n regard to [f]aculty appointments for which no reservations are in force, other things being equal, preference [is] given to candidates belonging to SC/ST." This "policy" has been incorporated into IIMB's Recruitment and Service Rules since July 15 1999. Between 2013 and 2017, IIM Bangalore interviewed 62 candidates from which it hired 20 candidates but at no stage in the process did it ask if the candidates belonged to SC or ST groups. When asked for documents which operationalizes this "policy," IIMB, indicated through another RTI response that it had "no information" of this nature. Similarly, IIM Lucknow, in a reply to information sought by MHRD (in the context of a question raised by a Lok Sabha member), observed that "[n]o reservation is maintained for recruitment of faculty positions. However, preference is given to candidates belonging to the reserved categories, if they are otherwise found suitable." However, when asked about category wise data on candidates interviewed and hired since the policy was put in place in Dec 2015, IIM-Lucknow responded that "[n]o data on caste [was] available." IIM Calcutta (IIMC) in their responses first asserted that "[h]istorically, the caste information has not been sought from faculty applicants" but also later note that "[t]he Board of IIM Calcutta has deliberated [... and] advised that whenever other suitability [sic] measures are the same, preference may be given to reserved category applicants if the category information is revealed" (emphasis added).

4 For example, several IIMs resorted to this excuse while responding to a communication dated 29.11.2016 from MHRD in relation to a Lok Sabha Unstarred Question No. 3946 from August 2014, titled 'Backlog of Vacancies' (an answer to the question is yet to be tabled as of June 2017). The communication sent to directors of all the then existing 13 IIMs asked inter alia, "whether the backlog of vacancies in teaching positions in SC/ST categories exists in the educational institutions especially in Universities, Indian Institutes of Technology (IITs) and Indian Institutes of Managements (IIMs)." In response to the MHRD missive, several IIMs including Ahmedabad, Bangalore and Calcutta responded in the affirmative. The Director of IIM Bangalore in his response indicated that "IIM Bangalore does find the number of applicants who satisfy the requirements for a faculty position is relatively small." IIM Raipur responded that "[a]s per the Government of India policy on reservation for the reserved categories (SC, ST and $\mathrm{OBC})$, the Institute provides relaxation in the eligibility criteria for the faculty positions as per guidelines provided by the Ministry of HRD. At the time of advertisement, it is clearly mentioned that the reservation policy enunciated by the Government of India is followed by the Institute. However, it has been observed that very few applications from SC and ST category could be shortlisted for interview even after applying the relaxed eligibility criteria in the requirements carried out in the past. It is also pertinent to highlight that out of the few shortlisted candidates, none was found for selection by the selection committee." These responses from IIMs were obtained from MHRD through an RTI query.

5 In response to a RTI query which asked if "the provisions of reservations for SC and ST apply to admissions to Fellow Programme in Management (FPM) in Indian Institutes of Management (IIMs)," 
MHRD responded that "IIMs, IISERs and IISc Bangalore... all of them are expected to follow the Central Educational Institutes (Reservation in Admission) Act, 2006." RTI responses from various IIMs only the following institutions currently (but not necessarily historically) implement quota based reservations in their FPM admissions - IIM Calcutta, IIM Raipur, IIM Ranchi, IIM Shillong, and IIM Tiruchirapalli.

6 In our RTI applications, we sought information about whether IIMs implement the provisions of the Central Educational Institutions (Reservation in Admission) Act, 2006, which provide for reservations for seats in Central Educational Institutions out of the "annual permitted intake". In its response, the institution that pioneered the null matrix argument - IIM Ahmedabad - stated that "[t]here is no annual permitted intake specified for FPM at IIMA and therefore reservation cannot be specified" (emphasis added). IIM Kozhikode responded: "[a]s there is no upper limit stipulated in respect of intake for admission to the FPM of IIM Kozhikode, no specific quota is fixed for different category of candidates." IIM Lucknow in its response stated that "the admission to FPM is not against specific number of seats. The annual intake depends on the availability of candidates who fulfill the prescribed eligibility criteria which include the candidates' performance in admission test, academic qualifications, work experience, personal interview, etc." In a clear statement of how the null matrix argument operates, IIM Indore in its response stated that: "[y]es, the norm of reservation is applicable to this [i]nstitute for all programmes . However as there is no upper limit stipulated for admission to the Fellow Programme in Management (FPM), no specific quota is fixed for different category of candidates." If the IIMs responded in negative, we asked them to provide "the relevant Government Order or Government Letter or communication or Court judgment" that exempts them from the provisions of the Central Educational Institutions (Reservation in Admission) Act, 2006. None of the eight IIMs not implementing these provisions could provide any case law/GO/Letter that exempts them from the aforesaid provisions.

7 For example, IIM Ahmedabad in response to a RTI query, acknowledged that it operates a wait-list for doctoral admissions. IIM-Ahmedabad described the process of wait-list in following terms: "[i]f a student doesn't accept offer of admission to particular area, then the next candidate on wait-list, if any, for that particular area, is offered admission." For admission year 2017-18, IIM Ahmedabad had notified 10 wait-listed candidates.

8 For example, at IIM-Lucknow (that does not implement reservation in its FPM programme) collects social group data from its admitted students. Between 2012 and 2017, it admitted 67 doctoral students with the following social group breakup - SC=3, ST=2, OBC $=2$ (out of these seven scholars, four were admitted in 2016-17). In other words, the diversity deficit at IIM-Lucknow over these five years was $39 \%$ - twice our conservative assumption of $20 \%$. Anecdotal evidence suggests that the three largest programmes at Ahmedabad, Bengaluru, and Kolkata will likely have a deficit that is larger than at Lucknow. NIRF (National Institutional Ranking Framework) filings in 2017, IIM-Bangalore reported no SC/ST/OBC doctoral scholar from the total of 134 scholars across all cohorts. IIM-Ahmedabad reported 8 such scholars out of a total program strength of 93 (for a deficit of over $40 \%$ ). The NIRF filing from IIMCalcutta once again indicates a deficit of over 40\% (9 of 96 doctoral scholars at IIM Calcutta were from SC/ST/OBC groups at the time of NIRF 2017 filing). The diversity deficit is more acute than what the NIRF data suggests as the dropout rate among SC/ST scholars is likely to be higher than the overall rate (Thakur and Babu, 2017). 